\title{
A New 2D-Based Method for Carotid Intima-Media Thickness Quantification From Ultrasound Sequences
}

\author{
Mehravar Rafati ${ }^{1}$; Mehrdad Rafati Rahimzadeh ${ }^{2}$; Fariba Raygan ${ }^{3}$; Vahid Nikseresht $^{4, *}$; \\ Hassan Moladoust ${ }^{4}$ \\ ${ }^{1}$ Department of Medical Physics and Radiology, Faculty of Paramedicine, Kashan University of Medical Sciences, Kashan, IR Iran \\ ${ }^{2}$ Department of Nursing, Babol University of Medical Sciences, Babol, IR Iran \\ ${ }^{3}$ Department of Cardiology, Faculty of Medicine, Kashan University of Medical Sciences, Kashan, IR Iran \\ ${ }^{4}$ Department of Cardiology, Heshmat Cardiovascular Research Center, Guilan University of Medical Sciences, Rasht, IR Iran \\ *Corresponding Author: Vahid Nikseresht, Department of Cardiology, Heshmat Cardiovascular Research Center, Guilan University of Medical Sciences, P. O. Box: 41939-55588, Rasht, \\ IR Iran. Tel: +98-1333663070; Fax: +98-1336668718, E-mail: hmarefat2005@yahoo.com
}

Received: October 19, 2014; Revised: November 28, 2014; Accepted: January 26, 2015

\begin{abstract}
Background: Ultrasound measurement of carotid Intima-Media Thickness (IMT) is a suitable method to evaluate subclinical arteriosclerosis.

Objectives: The current study aimed to present a new computerized algorithm to detect instantaneous changes of the IMT to Common Carotid Artery(CCA) of IMT in sequential ultrasound images by applying the maximum gradient and the dynamic programming.

Patients and Methods: In a cross-sectional design, an examination was performed on thirty healthy human subjects with the mean age of $44 \pm 6$ years from April 2013 to June 2013 in Beheshti Hospital, Kashan, Iran. In all individuals, the instantaneous changes of the far wall IMT on the CCA were extracted. Local measurements of vessel intensity, intensity gradient, and boundary continuity were extracted for all of the sequential ultrasonic 2D-frames throughout three cardiac cycles. The Pearson correlation coefficients and Bland-Altman analysis were performed to assess the relationship and agreement between IMT measured by the proposed and conventional manual methods. Results: There was no significant difference between the proposed and manual methods with paired t-test analysis (in systole: $0.57 \pm 0.10$ vs. $0.56 \pm 0.10 \mathrm{~mm} ; \mathrm{P}=0.188$ and in diastole: $0.63 \pm 0.16$ vs. $0.62 \pm 0.10 \mathrm{~mm} ; \mathrm{P}=0.122$ for the manual and proposed methods, respectively). The Pearson correlation coefficients were $r=0.94$ and $r=0.93$ for IMT and IMT $_{d}$, respectively (both $\mathrm{P}<0.001$ ). Limit of agreements were narrow and considerable agreement was found between the two methods.

Conclusions: The present study demonstrated that the proposed computerized analyzing method can provide accurate measurements of the IMT of the CCA in sequential 2D ultrasonic images.
\end{abstract}

Keywords: Carotid Intima-Media Thickness; Image Processing, Computer-Assisted; Ultrasonography; Cardiovascular Diseases

\section{Background}

Vascular complications due to atherosclerosis are a main cause of death worldwide (1). Atherosclerosis, which is the major risk factor, is accelerated in Cardiovascular Diseases (CVD). Therefore, detection and quantification of atherosclerosis disease is important to monitor treatment and the possible restrictions of acute events $(2,3)$. Angiography is the gold standard method to evaluate arterial lesions in medical research, but it has some disadvantages such as being invasive, surgical complications, and ionizing radiation risks; therefore, it is not a good screening tool. Hence, a non-invasive assessment method that is away from ionizing radiation risks to the prognosis of this fatal injury can be effective in the treatment (4).

Recent improvements of ultrasound systems provide a non-invasive evaluation of arteries. Evaluation of artery sonography with B-mode method, including carotid artery is a simple and quantitative method. It not only shows the structural and functional changes in the ca- rotid artery but it is also a non-invasive method for early diagnosis of atherosclerosis in artery wall $(5,6)$.

Different types of arterial wall markers such as arterial wall thickening and stiffening, endothelial dysfunction and coronary artery calcification are currently available (7-9). Among them, Intima-Media Thickness (IMT) is a safe, simple, and inexpensive method to assess subclinical atherosclerosis, and an independent index of atherosclerosis events (10). In sonography with B-mode method, wall thickness and vessel diameter can be directly measured since image acquisition of arterial wall can be obtained in a dynamic behavior throughout the cardiac cycle as the artery expands and contracts with each cardiac pulsation and relaxation, respectively (6). Repeated measurement of the arterial walls is possible by this technic, but most researchers use manual tracing to evaluate arterial properties $(10,11)$, which is unreliable since it is based on subjective operator assessment and is time-consuming. Some studies suggest that an automated algorithm to measure

Copyright (C) 2015, Iranian Red Crescent Medical Journal. This is an open-access article distributed under the terms of the Creative Commons Attribution-NonCommercial 4.0 International License (http://creativecommons.org/licenses/by-nc/4.0/) which permits copy and redistribute the material just in noncommercial usages, provided the original work is properly cited. 
arterial properties is preferable. The automated techniques offer a lot of benefits. They are proper for ample database multi-center studies. The automated algorithms ease the design of multiple original equipment manufacturing data comparisons. Moreover, they lay the foundation for better accuracy and reproducibility of the studies and raise the specificity of the overall system by preventing the subjective settings. Finally, automated techniques reduce the laborious and tedious operator dependency in ultrasound IMT measurements (11-14).

\section{Objectives}

Besides the above-mentioned matters, substantial temporal variability in IMT during systole and diastole and among cardiac cycles is not widely used in clinical practice (15). To improve hindrances to the clinical implementation of carotid IMT changes as a risk assessment tool, the current study aimed to evaluate IMT changes on common carotid artery (CCA) throughout the cardiac cycle by the proposed computerized semi-automated method in sequential 2D ultrasound images.

\section{Patiants and Methods}

\subsection{Study Population}

In a cross-sectional design, an examination was performed on thirty subjects at a mean age of $40 \pm 5$ years from April 2013 to June 2013 through random sampling. The group study included healthy volunteers who referred to Beheshti Hospital affiliated to the Kashan University of Medical Sciences, Kashan, Iran. None of the subjects had a history of cardiovascular and/or cerebrovascular disease (all had normal physical examination, resting Electrocardiography (ECG), echocardiography and none was taking medicine), hypertension (blood pressure $<140 / 90$ $\mathrm{mmHg}$ ), diabetes mellitus (fasting blood glucose $<110 \mathrm{mg}$ / dL, HbA1c < 5.8\%), hypercholesterolemia (<220 mg/dL), and tobacco abuse (volunteers had never smoked) $(16,17)$. All subjects signed informed written consent prior to participation in the study. This study was approved by the ethics committees of Kashan University of Medical Sciences and Beheshti Hospital, Kashan, Iran (Iran; code ethical approval, 9139; approval date, 05/08/2012).

\subsection{Ultrasound Studies and Offline Analysis}

Before ultrasonography, the subjects rested for at least 10 minutes in the supine position until their heart rate and blood pressure reached a steady state. Blood pressure and heart rate were recorded with an oscilloscopic blood manometer (ALP K2, Adult Cuff, \pm 1 mmHg, Tokyo, Japan) and a wrist manometer (Microlife, $\pm 3 \mathrm{mmHg}$, Germany) on the left brachial and radial arteries with the subject in a supine position, respectively. Measurements were performed in a temperature-controlled room according to current guidelines (18).

The left CCA of the subjects, $2-3 \mathrm{~cm}$ proximal to the bifur- cation, was examined with a Sonoline Antares Ultrasound System equipped with a 5-13 MHz linear transducer (Siemens, Germany) by an expert sonographer in the radiology department at Beheshti Hospital. Dynamic range, gray level, and depth of focus were $55 \mathrm{~dB}, 0$ to 255, and $3.5 \mathrm{~cm}$, respectively (19). The Audio Video Interleaves (AVI) format of the consecutive images of the common carotid artery with a frame rate of 30 frames per second was transferred to a personal computer for post processing. The recording contained 90 frames (almost three cardiac cycles) while the left CCA was scanned in the longitudinal direction. The program was designed in MATLAB software version 7.0.1 (Math Software Co., Math Works, USA) to extract consecutive images in the bitmap image file format from the movies with Audio-Videio Inteleave (AVI) format (image size: $547 \times 692 \mathrm{pixel}^{2}$ ).

For offline analysis, proposed computerized analysis algorithm was used to detect instantaneous changes on the carotid IMT in sequential ultrasound images throughout three cardiac cycles. In this method, the reference points and the cost function were based on dynamic programming and a maximum gradient algorithm, respectively (20). The algorithm was run for measuring the instantaneous changes in the IMT of the common carotid artery relative to the probe. The first step was to select the examination scope for the longitudinal axis of the artery. The points were placed manually in middle of the far wall in CCA on the first image of the sequence. Then, by placing reference points on the top and bottom far wall of the common carotid artery, the estimated boundaries were formed (Figure 1). The points were connected by straight lines. The boundary point was selected in such a way that the gradient of the pixel maximized. The ultrasonic image pixel had a dimension of $0.06 \times 0.06 \mathrm{~mm}^{2}$. By interpolation, 100 boundary points were obtained, and by considering the measurements in three cardiac cycles, measuring error would become less than $0.005 \mathrm{~mm}$. The instantaneous changes in the carotid IMT were extracted by semi-automated computerized edge detection software (20). Application of the suggested method to all of the frames generated a sequence of IMT of CCA in three cardiac cycles. The IMT measurements determined by the presented method were evaluated for accuracy by comparison with conventional manual methods. The manual tracing was performed using Image Tools Software (Microsoft, Texas, USA) and the mean of the three measurements was used to determine the IMT in diastolic $\left(\right.$ IMT $\left._{d}\right)$ and systolic $\left(\right.$ IMT $\left._{s}\right)$ of the CCA.

\subsection{Statistical Analysis}

The statistical analyses were performed using SPSS version 13.0 software (SPSS Inc. Chicago, IL, USA). All of the continuous variables were presented as mean \pm Standard Deviation (SD). The data were tested for normal distribution using the Kolmogorov-Smirnov (K-S) test. To determine the significance of the differences in the values between the two methods, paired t-test analysis was performed. $\mathrm{P}$ value $\leq 0.05$ was considered statistically significant. 
Figure 1. A Typical Common Carotid Artery 2D B-Mode Sonographic Image
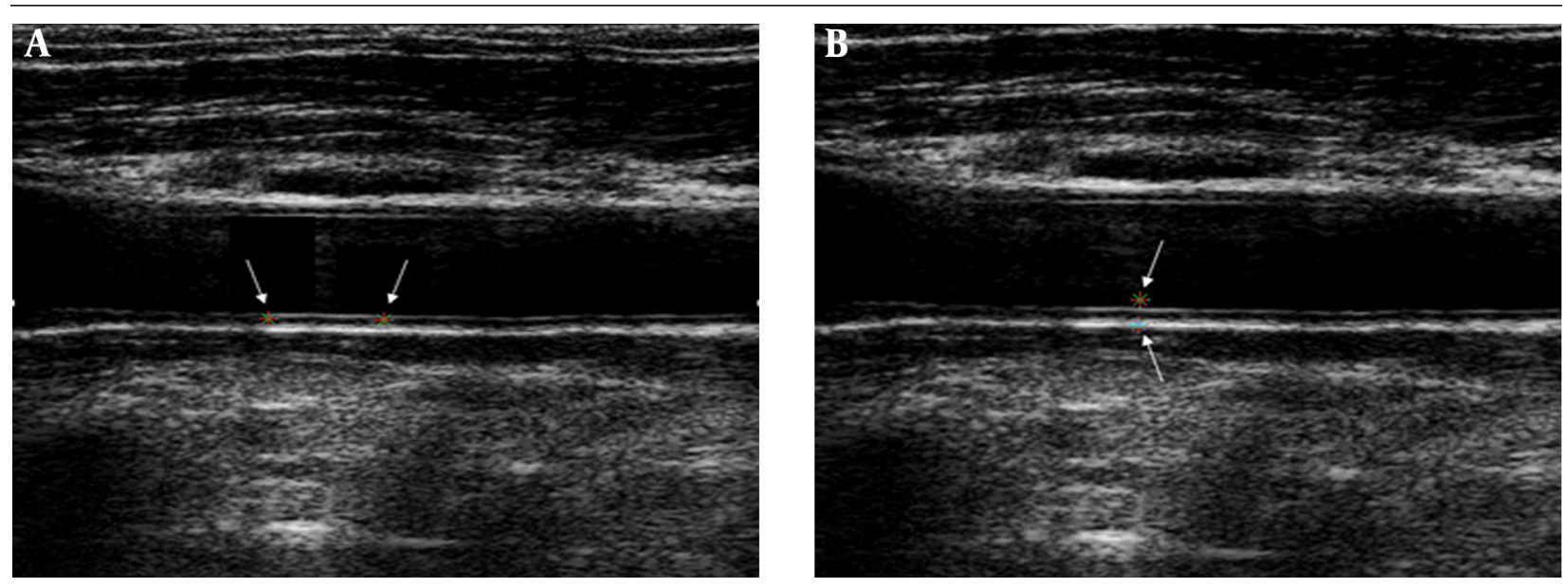

(A) Star markers represent the examination scope for the longitudinal axis in the middle of the far wall common carotid artery; (B)Star markers represent reference points in the far wall of the common carotid artery.

Pearson's correlation coefficient and linear regression functions between the results of the proposed and manual methods were estimated with $P$ value $\leq 0.05$. The agreement between the proposed and manual methods was analyzed according to Bland-Altman analysis (21). The required sample size for the study is as follows from Equation 1:

$$
n=\frac{\left(Z_{1-\frac{\alpha}{2}}+Z_{1-\beta}\right)^{2} \sigma^{2}}{\delta^{2}}
$$

Where $\mathrm{Z}_{1-\alpha, 2}$ is the normal deviate at a level of significance $\left(Z_{1-\alpha / 2}\right.$ is 1.96 for 0.05 level of significance), $Z_{1-\beta}$ is the normal deviate at $1-\beta \%$ power with $\beta \%$ of type II error $(0.84$ at $80 \%$ statistical power), $\sigma$ and $\delta$ are standard deviation and difference of means of pairs (22). Intraobserver variability (by one expert sonographer) and interobserver variability (by two expert sonographers) in 15 subjects were the differences between measurements expressed as a percentage of the error of the means. Reproducibility of each experiment was reported as a coefficient of variance percent (\%COV).

\section{Results}

The ultrasonic examination of the left CCA of thirty human subjects (aged $40 \pm 5$ years) with no history of cardiovascular and/or cerebrovascular diseases, hypertension, diabetes mellitus, and tobacco abuse was performed. Their Body Mass Index (BMI) was $25 \pm 2 \mathrm{~kg} / \mathrm{m}^{2}$; systolic pressure, $125 \pm 15 \mathrm{mmHg}$; diastolic pressure, $78 \pm 5 \mathrm{mmHg}$; and heart rate (HR), $72 \pm 5 \mathrm{bpm}$. All samples were male, holding high school diploma, 27 were married and three were single. The algorithm was run for measuring IMT changes in the far wall of the CCA throughout three cardiac cycles in all 30 subjects (Figure 2). Basically, the IMT of the artery wall was the thinnest during systolic phase at the point of peak arterial enlargement, and the thickest at diastolic phase when the artery diameter was the smallest. The results of $\mathrm{IMT}_{\mathrm{s}}$ and IMT $\mathrm{d}$ of the left CCA were presented in Table 1 . The statistical analysis showed no difference between the proposed and manual methods $(\mathrm{P}>0.05)$.

There was a significant correlation between the IMT measured by the proposed and manual tracing methods $\left(\mathrm{r}=0.94, \mathrm{P}<0.001\right.$ and $\mathrm{r}=0.93, \mathrm{P}<0.001$ for $\mathrm{IMT}_{\mathrm{s}}$ and $\mathrm{IMT}_{\mathrm{d}}$, respectively) (Figure 3 ). The linear regression analysis predicted the regression function between IMT $_{s}$ measured by manual tracing and the proposed methods as: $\mathrm{IMT}_{\mathrm{s}}($ manual $)=0.95 \mathrm{IMT}_{\mathrm{s}}($ proposed $)+0.03$

The regression function between IMT $_{d}$ measured by manual tracing and the proposed method was predicted as:

$\operatorname{IMT}_{\mathrm{d}}($ manual $)=0.96 \mathrm{IMT}_{\mathrm{d}}($ proposed $)+0.03$

Bland-Altman analysis indicated the difference between the estimated IMT changes and the middle line as the mean difference between the two methods, whereas the outer lines represent 1.96 SD or the $95 \%$ limits of agreement (LOA) (Figure 4). There was narrow LOA and considerably high agreement between the two methods. The mean difference for the measured IMT $_{s}$ and IMT $_{d}$ were $0.006 \pm 0.002 \mathrm{~mm}$ and $0.005 \pm 0.001 \mathrm{~mm}$, respectively.

Intraobserver and interobserver variabilities were 1.17 and $1.54 \% ; 2.04$ and $2.36 \%$ for IMT $_{\text {s }}$ of semi-automated and manual methods, respectively. Intraobserver and interobserver variabilities were $1.11 \%$ and $1.48 \% ; 2.12 \%$ and $2.47 \%$ for IMT $_{d}$ of the proposed and manual methods, respectively. The coefficient of variation percent (COV\%) in $\mathrm{IMT}_{\mathrm{S}}$ and $\mathrm{IMT}_{\mathrm{d}}$ for the proposed method was $18 \%$, and $16 \%$, respectively. The coefficient of variation percent (COV\%) in $\mathrm{IMT}_{\mathrm{s}}$ and $\mathrm{IMT}_{\mathrm{d}}$ for manual tracing was $26 \%$ and $28 \%$, respectively. 


\section{Rafati M et al.}

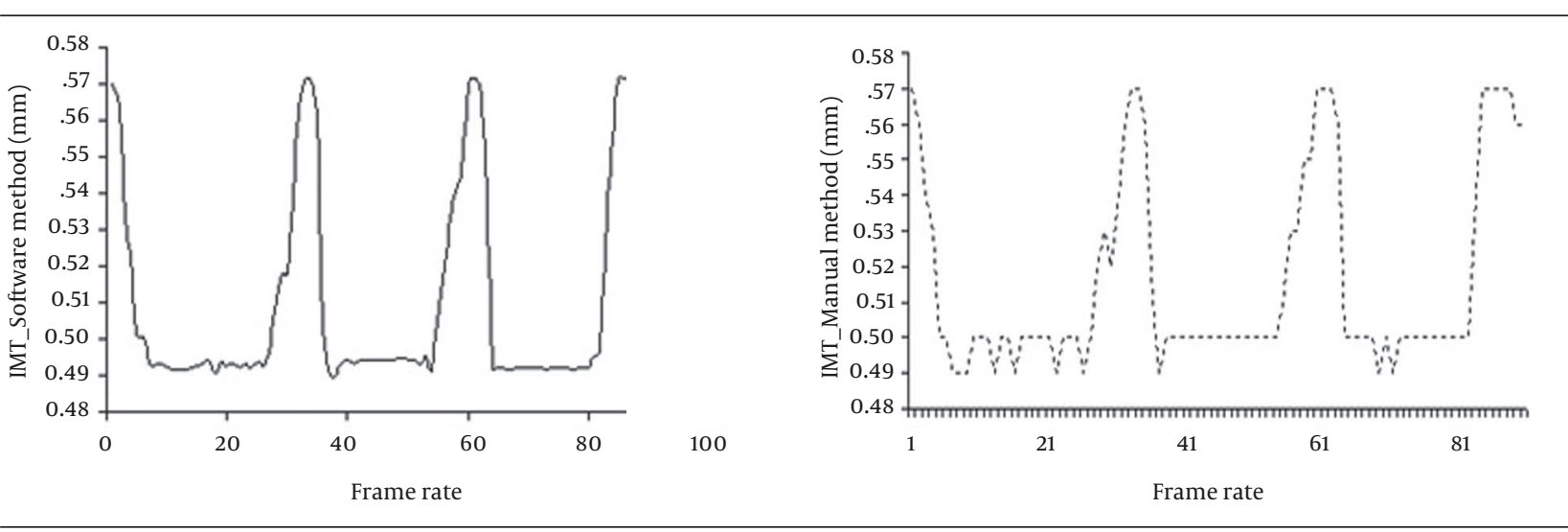

Figure 2. Instantaneous Changes in IMT of Common Carotid Artery by the Proposed Computerized Method, and Manual Method Throughout Three Cardiac Cycles, Respectively. Time resolution is 33 Milli second

Table 1. Comparison the changes of Intima-Media Thickness During Cardiac Cycles with the Proposed and the Manual Methods a

\begin{tabular}{lccc}
\hline Variables & Manual Method & Proposed Method & P Value \\
\hline IMT $_{s}, \mathbf{m m}$ & $0.57 \pm 0.10$ & $0.56 \pm 0.10$ & 0.188 \\
IMT $_{\mathrm{d}}, \mathbf{m m}$ & $0.63 \pm 0.16$ & $0.62 \pm 0.10$ & 0.122 \\
\hline
\end{tabular}

${ }^{\text {a }}$ Abbreviations: IMT $_{S}$, intima-media thickness in systolic phase; IMT $_{\mathrm{d}}$, intima-media thickness in diastolic phase.
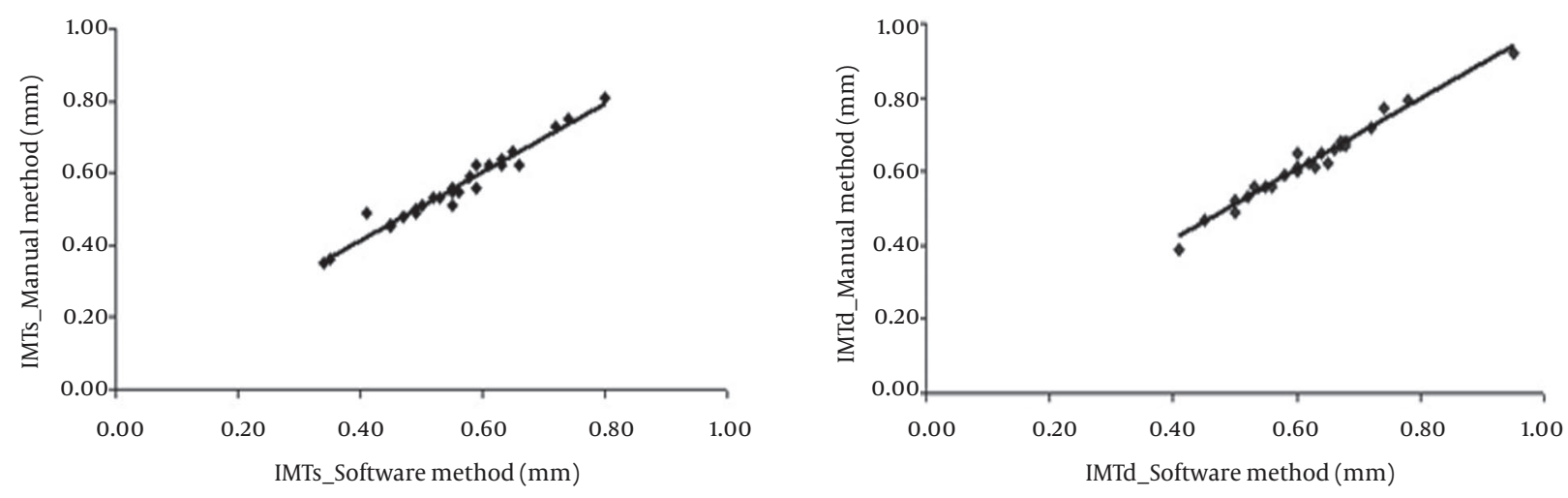

Figure 3. Scatter Plot Demonstrating the Correlations for IMT in Systolic Phase ( IMT $_{S}$ ) and IMT in Diastolic Phase (IMT ${ }_{d}$ ) Measurements Between Proposed Computerized Analysis and Manual Tracing
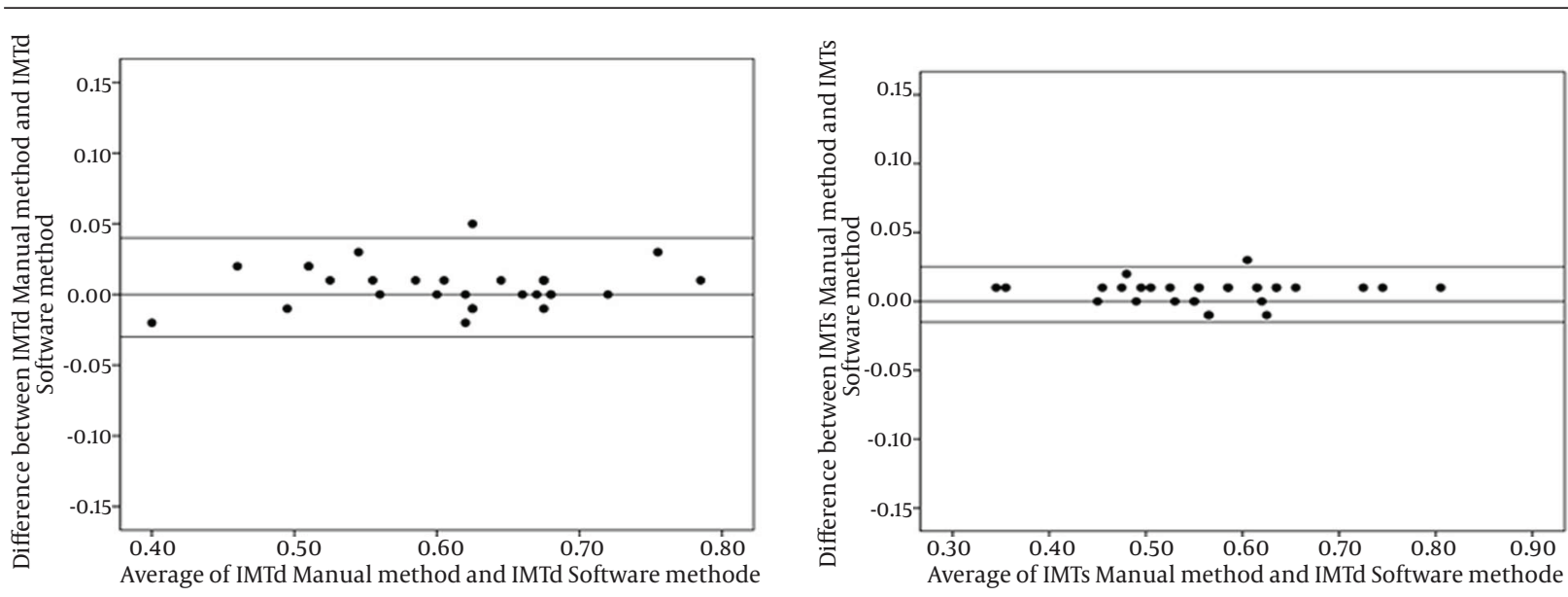

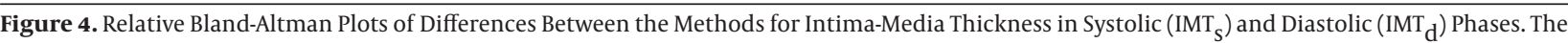
Outer Lines Represent 1.96 SD or 95\% Limits of Agreement (LOA) 
Rafati M et al.

\section{Discussion}

Although the pathogenesis of CVD is difficult, atherosclerosis is thought to play a major role. Preventive measures taken early in life might more properly overcome the cardiovascular disease epidemic by putting back atherosclerosis or delaying the occurrence of clinical CVD $(23,24)$. Since the carotid artery is proper to study, because of its superficial position and its relative thickness, considerable attention is recently directed to the CCA wall thickness as an early marker of asymptomatic cases over 40 years of age ,and it can have a predictive role for risk assessment (23). Jadhav et al. showed that detection of atherosclerosis in the CCA using B-mode ultrasound is a simple, noninvasive, and reproducible clinical method to evaluate atherosclerosis in patients with Coronary Artery Disease (CAD) (25). The CCA is close to the skin, pretty straight, and well imaged, allowing carotid IMT to be measured easily (26). Besides, the CCA is approximately a cylinder and allows the use of mathematical models to measure stiffness and compliance (27). According to these facts, the current study was performed on CCA. The early study demonstrated two double echogenic lines separated by a hypoechoic space in CCA. The distance between the two lines (B-mode image of IMT) was measured and correlated with the thickness of different compositions of layers evaluated by large and microscopic test (5). van den Oord et al.(28)illustrated the correlations between extravascular and intravascular ultrasound analysis and histology of near and far wall measurements in CCA. They showed a proper correlation between far wall measurement in CCA ultrasound and histological analyses, whereas there was poor correlation in near wall measurement of CCA between both examinations. Another study showed that the relationship between carotid IMT and risk factors were more potential for the far wall measurement rather than the near one (29). Other studies deduced that the inherent drawback and error in evaluation edges of the CCA near wall, as opposed to the leading edge of echogenic frameworks represented by an echolucent vessel lumen, explained the observed differences (30). According to these findings, the current study focused on the CCA. With B-mode ultrasound, IMT on CCA far wall can be measured by calculating the arterial movement during cardiac cycles. Moreover, repeated measurement of arterial function can be performed with B-mode ultrasound. This technique can evaluate atherosclerosis progression. In most studies, the manual tracing method is used to measure arterial diameter and IMT changes in cardiac cycle (12). The manual tracing method is not only subjective to operator assessment but also time-consuming (31). The current study showed that high resolution Bmode ultrasound can assess the wall properties of artery during the cardiac cycle using a computerized analysis method. Different image analysis algorithms were investigated for automated ultrasonic boundary detection including the dynamic programming, maximum gradient, model-based, and matched filter algorithms. These meth- ods were implemented to measure the IMT and internal diameter of arteries, and among them, dynamic programming and maximum gradient had the highest accuracy (32). Loizou et al. (33) used the dynamic programming algorithm to develop a computerized analyzing system to evaluate the boundaries of intima-media. Gutierrez et al. (34) used an automatic method to measure lumen diameter and IMT based on an active contour technique. They compared the automatic measurement of lumen diameter and IMT with the results obtained from manual tracing of the vessels. They showed that the automated method was a reproducible and reliable way of assessing lumen diameter and IMT in the carotid artery. Cheng et al. (35) proposed an automatic system to detect the IMT of the CCA using the snake techniques. They showed that computerized system had the potential to automatically detect the imtimal and adventitial layers without any manual correction. Jegelevicus et al. employed the dynamic programming and maximum-gradient algorithms to measure the IMT in a single frame, separately (8). They suggested the use of maximum gradient for IMT measurement. But all of the above-mentioned studies used a computerized analysis method to detect lumen diameter or IMT in a single frame, and methods to make the actual measurements over the entire cardiac cycle to capture the mechanical nature of the vessel are sparse. Whereas, dynamic programming algorithm has a higher accuracy than a maximum gradient algorithm, but a maximum gradient algorithm has a lower computation complexity than a dynamic programming algorithm, the current study combined them to measure arterial diameter and IMT in CCA. The reference points and the cost function were based on dynamic programming and a maximum gradient algorithm, respectively. Few researches showed that changes in IMT happen during cardiac cycle $(26,36)$. Selzer et al. showed that IMT on the far wall of CCA was higher at the end of diastole than the peak of systole in 24 samples (6). Polak et al. showed 5.3\% reduction in carotid IMT and the average change of IMT was $0.04 \mathrm{~mm}$ with high resolution M-mode imaging (37). The current study findings were in agreement with the abovementioned studies.

A limitation of the study was that the translation movement of the CCA which came from the probe movement during scanning and suppression of artery pulsating movements were more complicated. However, the current study concluded that these movements were less.

The present study demonstrated that the proposed computerized analyzing method can provide accurate measurements of the far wall IMT on the CCA in sequential 2D ultrasonic images. By this method, not only the variation in the results of manual tracing by observers decreased, but also the duration of image processing was considerably reduced.

\section{Acknowledgements}

Authors would like to thank Dr. Kamran Hami and Yaser 
Hamedian from radiology department of Beheshti Hospital at Kashan University of Medical Sciences, Kashan, IR Iran.

\section{Authors' Contributions}

Study concept, design and study supervision: Mehravar Rafatiand Vahid Nikseresht; analysis and interpretation of data, drafting and revision of the manuscript and statistical analysis: Hassan Moladoust, Vahid Nikseresht, Mehravar Rafati and Mehrdad Rafati Rahimzadeh; acquisition of data and critical revision of the manuscript for important intellectual content: Mehravar Rafati, Hassan Moladoust, Mehrdad Rafati Rahimzadeh and Fariba Raygan.

\section{Financial Disclosure}

There was no conflict of interest and no financial relationship with any institute, company and organization.

\section{References}

1. Goldstein LB, Bushnell CD, Adams RJ, Appel LJ, Braun LT, Chaturvedi $S$, et al. Guidelines for the primary prevention of stroke: a guideline for healthcare professionals from the American Heart Association/American Stroke Association. Stroke. 2011;42(2):517-84.

2. O'Donnell MJ, Xavier D, Liu L, Zhang H, Chin SL, Rao-Melacini P, et al. Risk factors for ischaemic and intracerebral haemorrhagic stroke in 22 countries (the INTERSTROKE study): a case-control study. Lancet. 2010;376(9735):112-23.

3. Ghanaati H, Golchin N, Motevalli M, Shakiba M, Jalali AH, Firouznia K. Carotid Doppler ultrasonography in preoperative assessment of coronary artery bypass graft surgery in an Iranian population: association between atherosclerosis risk factors and carotid stenosis. Iran J Radiol. 2009;6(3):125-9.

4. Begelman SM, Jaff MR. Noninvasive diagnostic strategies for peripheral arterial disease. Cleve Clin J Med. 2006;73 Suppl 4:S22-9.

5. Shetty S, George P, Venkatesha BM, Alva J. A study to correlate carotid intima thickness by B-mode ultrasonography in patients documented with coronary artery disease. Heart Views. 2011;12(4):157-60.

6. Selzer RH, Mack WJ, Lee PL, Kwong-Fu H, Hodis HN. Improved common carotid elasticity and intima-media thickness measurements from computer analysis of sequential ultrasound frames. Atherosclerosis. 2001;154(1):185-93.

7. Coll B, Feinstein SB. Carotid intima-media thickness measurements: techniques and clinical relevance. Curr Atheroscler Rep. 2008;10(5):444-50.

8. Jegelevicus D, Lukosevicius A. Ultrasonic measurements of human carotid artery wall intima-media thickness. Ultragrasas. 2002;2:43-7.

9. Molaei-Langroodi R, Kheirkhah J, Barzegar A, Mirboluok F, Heydarzadeh A, Ebrahimian F, et al. Prediction of Coronary Artery Disease by B-Mode Sonography. Int Cardiovasc Res J. 2010;4(3):131-3.

10. Simon A, Gariepy J, Chironi G, Megnien JL, Levenson J. Intimamedia thickness: a new tool for diagnosis and treatment of cardiovascular risk. J Hypertens. 2002;20(2):159-69.

11. Andonova S, Petkova D, Bocheva Y. Intima-media thickness of the carotid artery in OSAS patients. Perspect Med. 2012;1(1-12):160-3.

12. Perwaiz Khan S, Gul P, Khemani S, Yaqub Z. Determination of sitespecific carotid-intima media thickness: common-carotid artery and carotid bifurcation in hypercholesterolemia patients. PakJ Med Sci. 2013;29(5):1249-52.

13. Touboul PJ, Hennerici MG, Meairs S, Adams H, Amarenco P, Bornstein $\mathrm{N}$, et al. Mannheim Carotid Intima-Media Thickness and Plaque Consensus (2004-2006-2011). Cerebrovasc Dis. 2012;34(4):290-6.
14. Molinari F, Meiburger KM, Saba L, Acharya UR, Ledda G, Zeng G, et al.Ultrasound IMT measurement on a multi-ethnic and multi-institutional database: our review and experience using four fully automated and one semi-automated methods. Comput Methods Programs Biomed. 2012;108(3):946-60.

15. Polak JF, Pencina MJ, Meisner A, Pencina KM, Brown LS, Wolf PA, et al. Associations of carotid artery intima-media thickness (IMT) with risk factors and prevalent cardiovascular disease: comparison of mean common carotid artery IMT with maximum internal carotid artery IMT. J Ultrasound Med. 2010;29(12):1759-68.

16. Perk J, De Backer G, Gohlke H, Graham I, Reiner Z, Verschuren M, et al. European Guidelines on cardiovascular disease prevention in clinical practice (version 2012). The Fifth Joint Task Force of the European Society of Cardiology and Other Societies on Cardiovascular Disease Prevention in Clinical Practice (constituted by representatives of nine societies and by invited experts). Eur Heart J. 2012;33(13):1635-701.

17. European Stroke O, Tendera M, Aboyans V, Bartelink ML, Baumgartner I, Clement D, et al. ESC Guidelines on the diagnosis and treatment of peripheral artery diseases: Document covering atherosclerotic disease of extracranial carotid and vertebral, mesenteric, renal, upper and lower extremity arteries: the Task Force on the Diagnosis and Treatment of Peripheral Artery Diseases of the European Society of Cardiology (ESC). Eur Heart J. 2011;32(22):2851-906.

18. Laurent S, Cockcroft J, Van Bortel L, Boutouyrie P, Giannattasio C, Hayoz D, et al. Expert consensus document on arterial stiffness: methodological issues and clinical applications. Eur Heart J. 2006;27(21):2588-605.

19. Touboul PJ, Hennerici MG, Meairs S, Adams H, Amarenco P, Bornstein N, et al. Mannheim carotid intima-media thickness consensus (2004-2006). An update on behalf of the Advisory Board of the 3rd and 4th Watching the Risk Symposium, 13th and 15th European Stroke Conferences, Mannheim, Germany, 2004, and Brussels, Belgium, 2006. Cerebrovasc Dis. 2007;23(1):75-80.

20. Rafati M, Bitarafan-Rajabi A, Hami K. Performance Intima-Media Thickness of Carotid Artery and Flow Mediated Dilation of Brachial Artery for Assessing Atherosclerosis Progression. J Med Imaging Health Infor. 2014;4(5):724-32.

21. Bland JM, Altman DG. Statistical methods for assessing agreement between two methods of clinical measurement. Lancet. 1986;1(8476):307-10.

22. Gallin JI, Ognibene FP. Principles and practice of clinical research. 3d ed. Waltham, USA: Elsevier Inc; 2012. pp. 276-7.Power and sample size calculations.

23. Rabelo LM. Atherosclerotic risk factors in adolescence. J Pediatr (Rio J). 2001;77(Suppl 2):S153-64.

24. Gonzalez J, Wood JC, Dorey FJ, Wren TA, Gilsanz V. Reproducibility of carotid intima-media thickness measurements in young adults. Radiology. 2008;247(2):465-71.

25. Jadhav UM, Kadam NN. Carotid intima-media thickness as an independent predictor of coronary artery disease. Indian Heart J. 2001;53(4):458-62.

26. Menees S, Zhang D, Le J, Chen J, Raghuveer G. Variations in carotid artery intima-media thickness during the cardiac cycle in children. JAm Soc Echocardiogr. 2010;23(1):58-63.

27. Brasileiro AC, Oliveira DC, Victor EG, Oliveira DA, Batista LL. Association between ankle-brachial index and carotid atherosclerotic disease. Arq Bras Cardiol. 2013;100(5):422-8.

28. van den Oord SC, ten Kate GL, Akkus Z, Renaud G, Sijbrands EJ, ten Cate FJ, et al. Assessment of subclinical atherosclerosis using contrast-enhanced ultrasound. Eur Heart J Cardiovasc Imaging. 2013;14(1):56-61.

29. Abd El-Hafez H, Elrakhawy MM, El-Baiomy AA, El-Eshmawy MM. Carotid Intima Media Thickness Is Independently Associated with Male Gender, Middle Age, and IGF-1 in Metabolically Healthy Obese Individuals. ISRN Obes. 2014;2014:545804.

30. Urbina EM, Williams RV, Alpert BS, Collins RT, Daniels SR, Hayman L, et al. Noninvasive assessment of subclinical atherosclerosis in children and adolescents: recommendations for standard assessment for clinical research: a scientific statement from the American Heart Association. Hypertension. 2009;54(5):919-50. 


\section{Rafati M et al.}

31. Rubins U, Marcinkevics Z, Volceka K. The method of evaluation artery diameter from ultrasound video. World Acad Sci Eng Technol. 2010;69:692-4.

32. Ojaghi-Haghighi Z, Moladoust $\mathrm{H}$, Shojaeifard M, Asadinezhad M, Nikseresht V. A Comparison between methods used to extract maximum and minimum myocardial velocities by spectral pulsed-TDI. Iran Cardiovasc Res J. 2011;5(2):50-5.

33. Loizou CP, Kasparis T, Lazarou T, Pattichis CS, Pantziaris M. Manual and automated intima-media thickness and diameter measurements of the common carotid artery in patients with renal failure disease. Comput Biol Med. 2014;53:220-9.

34. Gutierrez MA, Pilon PE, Lage SG, Kopel L, Carvalho RT, Furuie SS
Automatic measurement of carotid diameter and wall thickness in ultrasound images. iee explore. 2002(7).

35. Cheng DC, Schmidt-Trucksass A, Cheng KS, Burkhardt H. Using snakes to detect the intimal and adventitial layers of the common carotid artery wall in sonographic images. Comput Methods Programs Biomed. 2002;67(1):27-37.

36. Kanai H, Koiwa Y. Real-time velocimetry for evaluation of change in thickness of arterial wall. Ultrasonics. 2000;38(1-8):381-6.

37. Polak JF, Johnson C, Harrington A, Wong Q, O'Leary DH, Burke G, et al. Changes in carotid intima-media thickness during the cardiac cycle: the multi-ethnic study of atherosclerosis. J Am Heart Assoc. 2012;1(4):e001420. 